\title{
Endoscopic submucosal dissection for superficial esophageal cancer overlying a submucosal tumor originating from the muscularis propria
}

A 62-year-old man was referred to our hospital for treatment of an esophageal cancer overlying a submucosal tumor (SMT). The SMT was present in the middle thoracic esophagus, and endoscopic ultrasonography (EUS) demonstrated a hypoechoic tumor with calcification inside, originating from muscularis propria. We diagnosed it as a benign tumor, such as a leiomyoma, and it underwent no change in size or form after 8 years of follow-up. The cancer however was superficial, and magnifying endoscopy combined with narrow-band imaging (NBI) revealed tortuous $\mathrm{B} 1$ vessels with irregular diameters and shapes. The biopsy specimen revealed squamous cell carcinoma, and endoscopic submucosal dissection (ESD) was therefore performed ( Fig. 1).

At first, we attempted to make an incision in the oral and anal sides using a DualKnife and then to add the circumferences using an IT knife nano. However, fluent endoscopic maneuverability in proximity to the SMT was difficult because the endoscope came into contact with the SMT, particularly during the incision on the anal side, which passed across the SMT and in a valley between the SMT and normal mucosa. Therefore, we used an SB Knife Jr for the incision and submucosal dissection of these sites. The SB Knife Jr is a scissor-type knife, which is available for dissection with a fixing endoscope, thereby preventing inadvertent injury to the muscular layer and promoting safe ESD [1]. Furthermore, we employed a clip-with-line method to dissect effectively. We achieved successful ESD of the overlying cancerous mucosa alone, without any complications in a procedure lasting 100 minutes ( $\triangleright$ Fig. 2; $\triangleright$ Video 1 ).

This is the first case report of a cancer overlying an SMT originating from muscularis propria that was successfully treated by curative ESD [2-4]. Based on our experience, we emphasize the im-
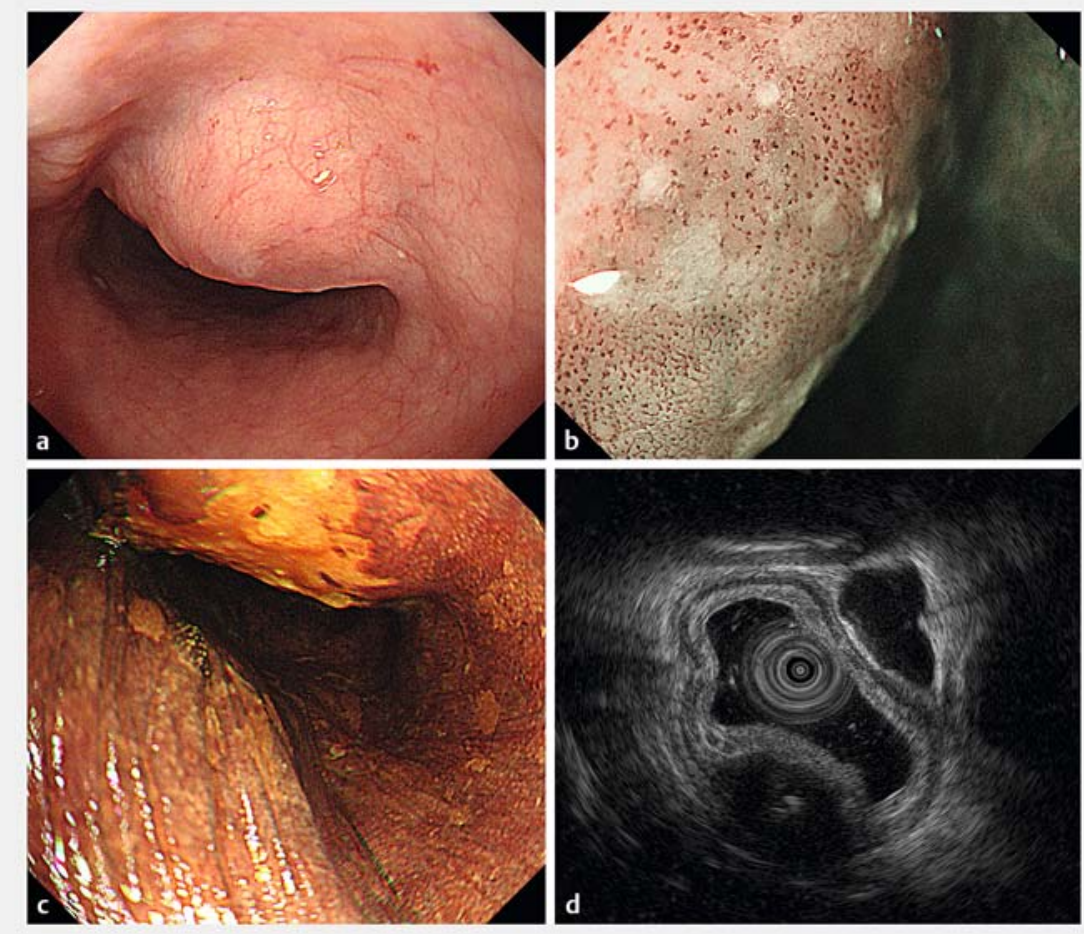

- Fig. 1 Imaging of the superficial esophageal tumor and submucosal tumor: a on endoscopy, showing the lesions in the middle thoracic esophagus; $\mathbf{b}$ on magnifying endoscopy combined with narrow-band imaging (NBI), showing loop-like abnormal vessels with dilation, and irregular diameters and shapes in the intraepithelial carcinoma; c non-staining of the tumor with iodine; $\mathbf{d}$ on endoscopic ultrasonography, showing a hypoechoic lesion of $15 \mathrm{~mm}$ in diameter originating from the muscularis propria.

portance of EUS to define the layer from which the SMT originates and the use of $\mathrm{NBI}$ magnifying endoscopy to diagnose invasion depth, followed by determination of an adequate endoscopic resection strategy. In addition, an SB Knife and traction-assisted strategy were efficient and effective for safe endoscopic treatment.

Endoscopy_UCTN_Code_TTT_1AO_2AG

Competing interests

None
The authors

Rino Nankinzan ${ }^{1}$, Takuto Suzuki ${ }^{1}$, Yoshiyasu Kitagawa', Taketo Yamaguchi ${ }^{2}$

1 Department of Endoscopy, Chiba Cancer Center, Chiba, Japan

2 Department of Gastroenterology, Chiba Cancer Center, Chiba, Japan

Corresponding author

Rino Nankinzan, MD

Endoscopy Division, Chiba Cancer Center, 666-2 Nitonacho, Chuo-ku, Chiba, Japan Fax: +81-43-2628680

rnankinzan@chiba-cc.jp 

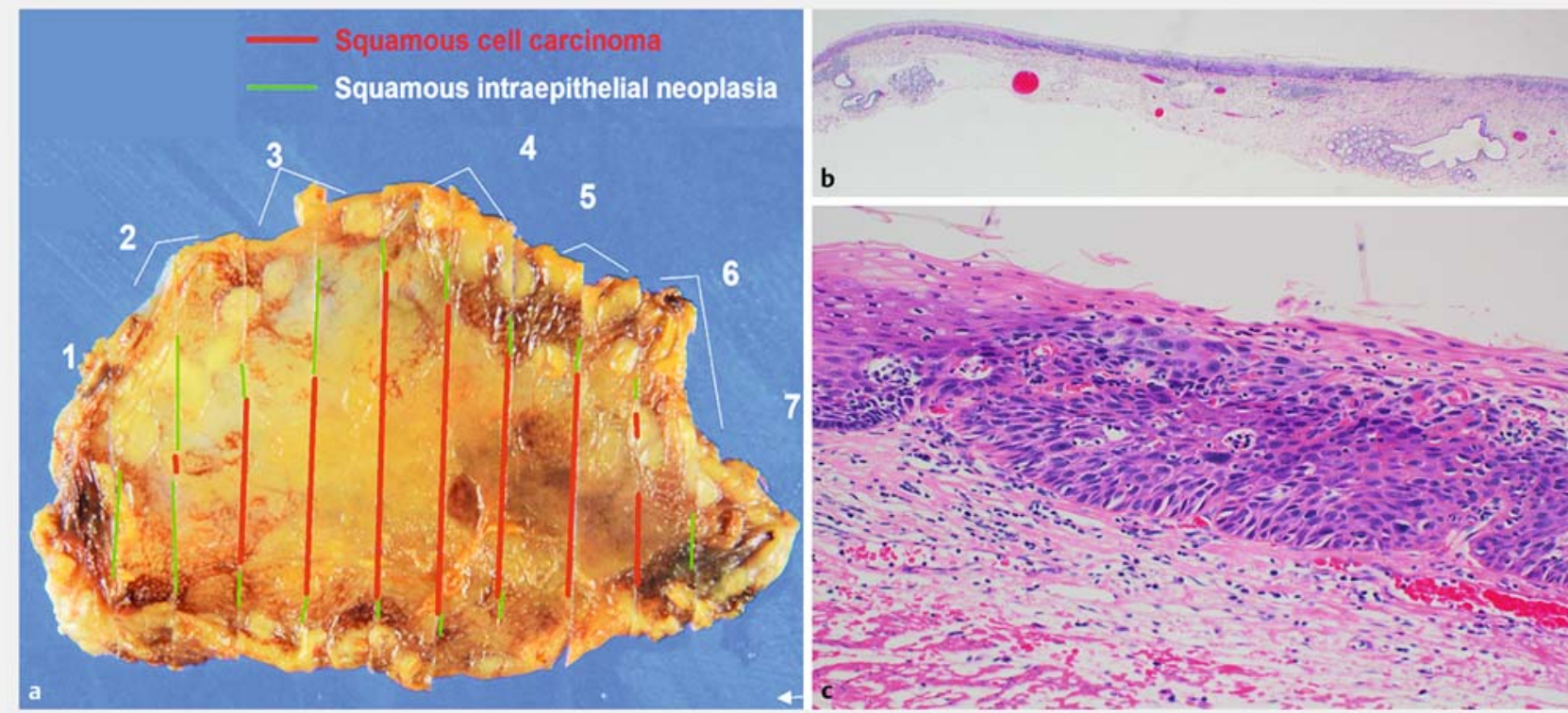

Fig. 2 Pathology of the resected specimen showing: a a mixed lesion, which was found to be a 20-mm squamous cell carcinoma with an area of squamous epithelial neoplasia; b, $\mathbf{c}$ (on section 4 stained with hematoxylin and eosin [H\&E]) that the invasion depth was to the lamina propria mucosa and there was no lymphovascular involvement with a negative cut end.

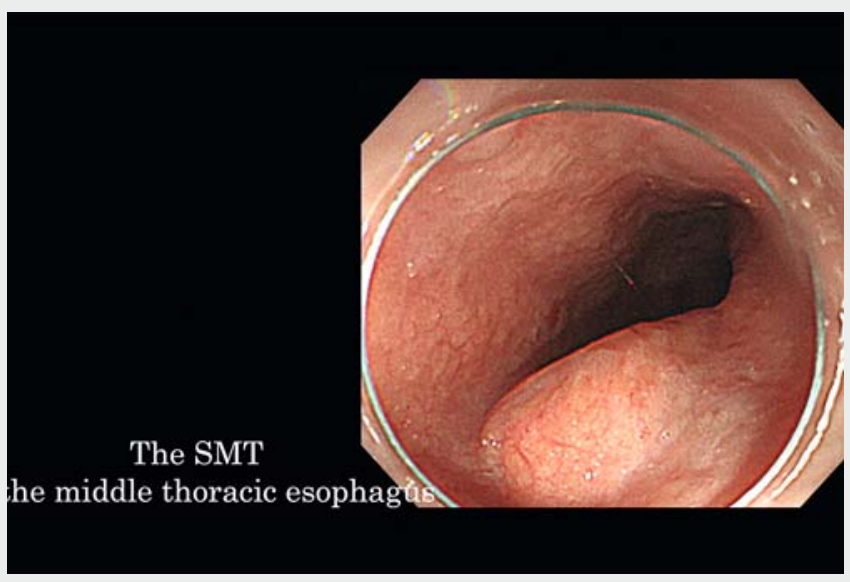

$\checkmark$ Video 1 Video showing successful endoscopic submucosal dissection of an esophageal cancer overlying a submucosal tumor that was originating from the muscularis propria using the SB Knife Jr and a traction-assisted strategy.

\section{References}

[1] Kuwai T, Yamaguchi T, Imagawa H et al. Endoscopic submucosal dissection for early esophageal neoplasms using the stag beetle knife. World J Gastroenterol 2018; 24: $1632-1640$

[2] Ishihara R, Yamamoto S, Yamamoto $S$ et al. Endoscopic resection of the esophageal squamous cell carcinoma overlying leiomyoma. Gastrointest Endosc 2008; 67: $745-747$

\section{Bibliography}

DOI https://doi.org/10.1055/a-0919-4278

Published online: 1.7.2019

Endoscopy 2019; 51: E358-E359

(c) Georg Thieme Verlag KG

Stuttgart · New York

ISSN 0013-726X

\section{ENDOSCOPY E-VIDEOS}

https://eref.thieme.de/e-videos

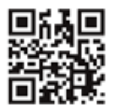

Endoscopy E-Videos is a free access online section, reporting on interesting cases and new techniques in gastroenterological endoscopy. All papers include a high quality video and all contributions are freely accessible online.

This section has its own submission website at

https://mc.manuscriptcentral.com/e-videos 